http://jmscr.igmpublication.org/home/ ISSN (e)-2347-176x ISSN (p) 2455-0450 crossref DOI: https://dx.doi.org/10.18535/jmscr/v8i5.56

\title{
Pattern of Gynaecological Total Abdominal Hysterectomy (TAH) in Abeokuta, Southwest Nigeria; a Five-Year Review
}

Authors

\author{
Olaide R. Adenaya ${ }^{1 *}$, Oluwole O. Ojo ${ }^{2}$, Adedoyin O. Ade-Onojobi ${ }^{3}$
}

${ }^{1,3}$ Department of Obstetrics and Gynaecology, Federal Medical Centre, Abeokuta, Ogun State, Nigeria

${ }^{2}$ Department of Obstetrics and Gynaecology, Gbagada General Hospital, Gbagada, Lagos, Nigeria *Corresponding Author

Olaide R. Adenaya

Department of Obstetrics and Gynaecology, Federal Medical Centre, Abeokuta, Ogun State, Nigeria

\begin{abstract}
Background: Total abdominal hysterectomy (TAH) is a common gynaecological operation and rarely obstetric. Indications for TAH may be benign or malignant and it is one of the most commonly performed surgical operations worldwide.

Aim: To describe the frequency, indications and complications of total abdominal hysterectomy (TAH) at a tertiary health institution in Abeokuta, Southwest Nigeria over a five-year period.

Methods: It was a 5-year descriptive retrospective study of all the total abdominal hysterectomies performed at our centre; a tertiary health institution in Abeokuta, Southwest Nigeria between January 2013 and December 2017. Case notes of 87 TAHs performed during the period were retrieved and analysed.

Results: There were 94 cases of TAHs out of a total of 515 major gynaecological surgeries during the period giving a TAH rate of $18.3 \%$ of major gynaecological surgeries. Eighty-seven (92.6\%) of the case notes were retrieved for analysis. Average parity of the patients was 2.9. Uterine fibroid was the most common indication constituting $81.6 \%$ of all the cases. Intra-operative blood loss ranged from $300 \mathrm{mls}$ to $1600 \mathrm{mls}$ with an average of $553.44 \mathrm{mls}$. Forty-four (50.6\%) patients lost less than $500 \mathrm{mls}$ of blood. Postoperative anaemia in 35 (40.2\%), and pyrexia in 11 (12.6\%) patients were the most common complications.

Conclusion: Total abdominal hysterectomy is a common gynaecological procedure. It is indicated in both benign and malignant gynaecological conditions. Uterine fibroid was the most common indication. Post-operative anaemia and pyrexia were the most common complications. It is apparent that proper optimization of patients prior to surgery is necessary to prevent post-operative anaemia.
\end{abstract}

Keywords: Pattern, Gynaecological, Total abdominal Hysterectomy, Indications, Complications.

\section{Introduction}

Hysterectomy is a surgical procedure which involves the removal of the uterus with or without the cervix. In some conditions, the fallopian tubes and the ovaries are removed in addition. It is the most commonly performed gynaecologic surgery worldwide. $^{1,2}$ As at 1999, approximately 600,000 hysterectomies were performed annually in the United States, and approximately 20 million U.S. women had had a hysterectomy. ${ }^{3}$ The overall rate of 
hysterectomy in Germany was 362 per 100000 person-years. ${ }^{4}$ The number of hysterectomies performed in many developed countries has fallen markedly as a result of more conservative measures for the management of dysfunctional uterine bleeding. ${ }^{1}$ The falling prevalence seen in the developed countries may reflect a variation in the practice of limiting hysterectomy and a shift to conservative treatments like increased use of ablative methods, hysteroscopic procedures, and the levenorgestrel releasing intrauterine device for gynaecological conditions. ${ }^{1,2,5}$ The prevalence of hysterectomy in developing countries however remained lower than that of developed countries. The lower prevalence of hysterectomy is due to fear of surgery, loss of feminity and sexual rejection by their spouses or because of their strong cultural belief or religious attachment to preservation of menstruation and childbearing. ${ }^{6}$ Total abdominal hysterectomy rates of $3.3 \%$ to $18.2 \%$ of major gynaecological surgeries were reported in some tertiary health institutions in Nigeria. ${ }^{7,8,9,10}$

There are many indications for hysterectomy and the uterus can be removed using any of a variety of techniques and approaches, including abdominal, vaginal, laparoscopic or robotic. ${ }^{11}$ Abdominal hysterectomy is the most common approach accounting for $84.8 \%-92.1 \%$ of all hysterectomies performed in Nigeria, while vaginal hysterectomy accounts for the rest 7.9-15.2\%. ${ }^{12,13}$ Laparoscopic approach is still very rare in Nigeria and only very few laparoscopic hysterectomies have been reported $^{14,15,16}$.

Abdominal hysterectomy could be total or subtotal (also known as "supracervical") depending on whether the cervix is removed with the uterus or preserved. Total abdominal hysterectomy account for higher percentage of abdominal hysterectomies with reported rates as high as 93-94.5\% of abdominal hysterectomy in some centres in Nigeria. ${ }^{7,9}$ Total abdominal hysterectomy may be performed alone or with unilateral or bilateral salpingo-oopherectomy depending on the indication for the surgery and the age of the patient. ${ }^{4}$
Nationwide analyses of hysterectomies in Portugal and the US reported uterine fibroid as the most common indication for hysterectomy, ${ }^{17,11}$ while excessive menstrual bleeding/pain was the most common self-reported indication in India. ${ }^{18}$ Several studies in Nigeria also reported uterine fibroid as the leading indications for abdominal hysterectomy. $^{7,8,9,10}$ Other indications for total abdominal hysterectomy include dysfunctional uterine bleeding, endometriosis/adenomyosis, endometrial polyps, pelvic inflammatory disease, chronic pelvic pain, cervical intraepithelial neoplasia, endometrial hyperplasia, and some malignant lesions. ${ }^{7,8,9,10}$

Majority of women have relief from their symptoms after hysterectomy with associated high level of satisfaction with the procedure. ${ }^{19}$ The procedure is not without possible complications, though mortality and morbidity following total abdominal hysterectomy have reduced significantly over the years due to improvement in anaesthesia and operative techniques. Postoperative fever and infections account for the majority of complications. $^{7,8,10}$ Other complications include intra-operative haemorrhage requiring transfusion, post-operative anaemia, urinary tract injuries, bowel injuries/intestinal obstruction, pelvic haematoma/ abscess. $^{7,8}$

Though there have been reviews of hysterectomy in centres in Nigeria, there is none from our centre. This study becomes imperative as it offers the opportunity to establish a baseline for the pattern of total abdominal hysterectomy in our centre and also compare the findings with those found in other centres.

\section{Materials and Methods \\ Ethical Consideration}

Ethical permission to carry out the study was sought and approval obtained from the Hospital's Health Research Ethics Committee (HREC).

\section{Study Design}

This was a retrospective descriptive study among all women who had total abdominal hysterectomy in 
our centre within the study period of Jan 2013 and December 2017.

\section{Study Population}

The study population was made up of all gynaecological patients who had total abdominal hysterectomy performed on them for gynaecological conditions either as elective or emergency, during the study period.

\section{Inclusion Criteria}

All patients who had total abdominal hysterectomy performed on them for gynaecological conditions.

\section{Exclusion Criteria}

All gynaecological patients who had had hysterectomy performed on them prior to the study period.

\section{Data Collection}

This study was a 5-year retrospective review of all cases of total abdominal hysterectomy for both benign and malignant gynaecological conditions managed at our centre which is a tertiary health institution in Abeokuta, Southwest Nigeria from $1^{\text {st }}$ January 2013 through 31st December 2017. The sources of information were the hospital's medical record unit, gynaecological ward records and theatre records. Information was retrieved from the patients' case notes using the proforma data. A total of 94 total abdominal hysterectomies were performed during the period. Information regarding the socio-demographic characteristics, parity, indications for surgery, extent of surgery (that is TAH+/-unilateral/bilateral salpingo-oopherectomy), intraoperative and postoperative complications, length of hospital stay, associated morbidity and mortality pattern were collected.

\section{Data Analysis}

Information retrieved from the case files was coded and filled into a spread sheet. The data obtained were analysed using simple percentages and frequency tables. Quantitative variables were described using measures of central tendency ((mean, median) and measures of dispersion (range, standard deviation) as appropriate.

\section{Results}

There were 94 cases of gynaecological total abdominal hysterectomy out of a total of 515 major gynaecological surgeries during the period with total abdominal hysterectomy prevalence of $18.3 \%$ of major gynaecological surgeries. Out of the 94 of the abdominal hysterectomy cases, 87 (92.6\%) case notes were retrieved for analysis. All the total abdominal hysterectomy performed for gynaecological reasons were performed as elective operations.

Table 1 shows the socio-demographic status of the women who underwent TAH.

The age range of the women was 35 to 80 years; with a mean age of 47.32 years. Only one of them was 35 years. Majority of the women were between 41 and 50 years constituting $65.55 \%$. All the women had at least a primary level of education. Majority $(94.3 \%)$ of the women were married. Majority $(94.3 \%)$ of them were employed. Seventy-one $(81.6 \%)$ were multipara, fourteen $(16.1 \%)$ were primipara, $9(10.3 \%)$ were grandmultipara while two $(2.3 \%)$ were nullipara. The average parity was 2.9.

Ten $(11.5 \%)$ were post-menopausal while the remaining $77(88.5 \%)$ were perimenopausal or premenopausal

Twenty (23\%) had total abdominal hysterectomy (TAH) alone. Most of the women who had TAH alone were 50 years and below. Fifty (57.5\%) patients had bilateral salpingo-oopherectomy in addition to the TAH and majority of them 39 (78\%) were at least 46 years. Seventeen (19.5\%) had unilateral salpingo-oopherectomy in addition to the $\mathrm{TAH}$ thereby conserving one of the ovaries, and majority of them were also at most 50 years.

Table 2 shows the indications for TAH. Uterine fibroid was the most common indication constituting $81.6 \%$ of all the cases. This was followed by benign ovarian masses with a prevalence of $8 \%$.

The blood loss during the surgeries ranged from $300 \mathrm{mls}$ to $1600 \mathrm{mls}$ with an average of $553.44 \mathrm{mls}$. Most patients $(50.6 \%)$ lost less than $500 \mathrm{mls}$ of 
blood. Five $(5.7 \%)$ of the patients lost $1000 \mathrm{mls}$ or more, all were patients with uterine fibroids.

Table 3 shows the post-operative complications recorded. Anaemia was the most common postoperative complication, occurring in 35 (40.2\%) patients. Fifteen of the patients with anaemia were transfused, $2(13.33 \%)$ were transfused one pint of blood each, $12(80 \%)$ had 2 pints each and the remaining $1(6.67 \%)$ had 3 pints. Pyrexia was another common complication seen in $11(12.6 \%)$ patients. Wound infection was seen in three $(3.4 \%)$ of the patients while one patient had bladder injury which was detected and repaired intraoperatively. In all, $53(60.8 \%)$ women had complications while 34 (39.2\%) had no complications at all.

The total number of days on admission ranged between 5 and 21 days with an average of 9.7 days. Most (64.37\%) of the patients stayed 5-9 days in hospital while only $5.75 \%$ stayed at least 20 days. Table 4 shows the duration of stay in hospital after surgery. After surgery, the number of days patients remained on admission ranged from 3 to 10 days with average of 4.8 days. Sixty-two (71.26\%) patients spent less than five days on admission after operation, fourteen $(16.09 \%)$ spent between 5 and 6 days while only $11(12.65 \%)$ spent 7 days or more.

Table 1: Socio-demographic status of the women

\begin{tabular}{|c|c|c|}
\hline Age (Years) & Frequency & Percentages $(\%)$ \\
\hline $31-35$ & 1 & \begin{tabular}{l|l} 
& 1.15
\end{tabular} \\
\hline $36-40$ & 10 & 11.5 \\
\hline $41-45$ & 25 & 28.75 \\
\hline $46-50$ & 32 & 36.8 \\
\hline $51-55$ & 11 & 12.6 \\
\hline $56-60$ & 4 & 4.6 \\
\hline$>60$ & 4 & 4.6 \\
\hline Total & 87 & 100 \\
\hline $\begin{array}{ll}\text { Level } & \text { of } \\
\text { Education } & \end{array}$ & Frequency & Percentage (\%) \\
\hline Primary & 15 & 17.24 \\
\hline Secondary & 37 & 42.53 \\
\hline Tertiary & 35 & 40.23 \\
\hline Total & 87 & 100 \\
\hline Marital Status & Frequency & Percentages $(\%)$ \\
\hline Married & 82 & 94.25 \\
\hline Widow & 2 & 2.3 \\
\hline Divorced & 2 & 2.3 \\
\hline Separated & 1 & 1.15 \\
\hline Total & 87 & 100 \\
\hline Parity & Frequency & Percentages $(\%)$ \\
\hline 0 & 2 & 2.3 \\
\hline 1 & 14 & 16.1 \\
\hline 2 & 18 & 20.7 \\
\hline 3 & 24 & 27.6 \\
\hline 4 & 20 & 23 \\
\hline$\geq 5$ & 9 & 10.3 \\
\hline Total & 87 & 100 \\
\hline
\end{tabular}


Table 2: Indications for Surgery

Indication for Surgery
\begin{tabular}{|l|c|c|}
\hline Fibroids & Frequency & Percentages $(\%)$ \\
Endometrial Carcinoma & 4 & 81.6 \\
Endometrial Hyperplasia & 1 & 4.6 \\
Benign Ovarian Mass & 7 & 1.15 \\
Ovarian Malignancy & 2 & 8.05 \\
HGSIL & 2 & 2.3 \\
& & 2.3 \\
Total & 87 & 100 \\
\hline
\end{tabular}

Key: HGSIL- High Grade Squamous Intraepithelial Lesion.

Table 3: Post -operative Complications

Post-operative Complication
\begin{tabular}{|l|c|c|}
\hline Anaemia & Frequency & Percentages $(\%)$ \\
Pyrexia & 35 & 40.2 \\
Anaemia + Pyrexia & 11 & 12.6 \\
Wound Infection & 3 & 3.4 \\
Bladder injury & 1 & 3.4 \\
& & 1.2 \\
Total & 53 & 60.8 \\
\hline
\end{tabular}

Table 4: Length of hospital Stay after Operation.

\begin{tabular}{|c|c|c|}
\hline Days & Frequency & Percentage $(\%)$ \\
\hline$<5$ & 62 & 71.26 \\
\hline $5-6$ & 14 & 16.09 \\
\hline $7-10$ & 11 & 12.65 \\
\hline Total & 87 & 100 \\
\hline
\end{tabular}

\section{Discussion}

Hysterectomy is the most commonly performed gynaecological surgery throughout the world. ${ }^{1,2}$ Majority of the hysterectomies are performed through the abdominal route. ${ }^{17}$ In this study, the total abdominal hysterectomy (TAH) rate was $18.3 \%$ of all gynaecological surgeries performed. This was higher than the abdominal hysterectomy prevalence reported in Kano Northwest Nigeria and TAH rate in Benin-City South-South Nigeria and even higher than the rate reported for all hysterectomies generally in Port-Harcourt SouthSouth Nigeria and Lagos Southwest Nigeria (same region where this study was carried out). ${ }^{7,8,19,20}$ It was close to the prevalence of total abdominal hysterectomy in Jos, North central Nigeria, ${ }^{10}$ This may be attributable to the fact that some of the studies in these centres focused on hysterectomies done for benign conditions only. The prevalence in this study is however far lower than the $20.1 \%$ prevalence of hysterectomy in the total population of women aged 20 and older in the United State. ${ }^{21}$
The low prevalence rate in Nigeria compared to US and some other developed nations may be as a result of the desire of Nigerian women to preserve fertility, their aversion for surgery and cultural/ religious beliefs.

Majority of the women were married and multiparous with para 2 - 4 constituting $71.3 \%$. This is similar to the finding in Kano ${ }^{7}$ but different from findings in Jos, Benin and Gombe Northeast Nigeria where majority of the women were grandmultipara. $^{9,8,10}$ Most of the women who underwent TAH in this study were aged 41 to 50 years and similar to report from Kano and Jos, ${ }^{7,10}$ while the mean age of 47.32years is close to that reported in Gombe, Port-Harcourt and Zaria. 9,19,12 but higher than the mean age reported in Jos and Benin. ${ }^{10,8}$ Hysterectomy rate peaked at this age group because many of the women had completed their family sizes and were peri-menopausal or postmenopausal. The two nulliparous women who had hysterectomies in this study were postmenopausal while the majority of the primiparous women were 
also either post-menopausal or perimenopausal. The few number of nulliparous and primiparous women in this study compared to the multiparous women further pointed to preference of conservative management by pauciparous women rather than hysterectomy for their conditions in anticipation of having children in future.

Symptomatic uterine fibroid was the major indication for total abdominal hysterectomy in our centre and this is similar to findings in other study series $^{7,8,10,12,17}$. This may be attributable to the high prevalence rate of uterine fibroid our environment. Many of these patients often present with huge uterine fibroids and heavy menstrual bleeding with complete family size or being peri- or postmenopausal and thereby making it easier for them to opt for hysterectomy which is the definitive management for such conditions.

Benign ovarian mass was second most common indication in this study. This is similar to the study by Obilahi-Abhulimen et al where ovarian mass was also second most common indication, though with a higher incidence than in this study. ${ }^{19}$

Additional procedure performed with the TAHs was salpingo-oopherectomy, either unilaterally or bilaterally. In this study, $57.5 \%$ of the women had bilateral salpingo-oopherectomy. This is similar to a study in Nguru where $62.1 \%$ of hysterectomised women also had bilateral saipingo-oopherectomy. ${ }^{11}$ Bilateral ovariectomy was also commonly performed with hysterectomies generally in Germany, US and Portugal. ${ }^{4,1,7}$ The high rate of concomitant oophorectomy during hysterectomy could be explained by the peri-/post-menopausal status of most of our patients and the need to remove the ovaries prophylactically against malignancy in future.

Estimated blood loss was less than 500mls in 50.7\% of the women while $5.7 \%$ lost more than $1100 \mathrm{mls}$. Average estimated blood loss during surgery was $553.44 \mathrm{mls}$ which was close to the mean blood loss in Jos and Benin. ${ }^{10,8}$ Anaemia with a second day post-operative packed cell volume (PCV) of less than $30 \%$ was the most common complications seen in this study. This seems unexpected considering the estimated average blood loss, however this is probably due to the fact that most of the patients were almost in anaemic state or frankly anaemic due to menorrhagia which they often presented with prior to surgery. Many of them were transfused before surgery to optimize their PCV to at least $30 \%$. Most of the post-operative anaemia were mild or asymptomatic moderate anaemia and this reflected in the number of patients $(44.7 \%$ of patient with post-operative anaemia) transfused in the postoperative period. Pyrexia was second most common complication. This is in contrast to many other studies where pyrexia or wound sepsis were reported as the most common complications. ${ }^{7,9,10,19}$ Pyrexia occurring 24 hours after operations were investigated and were mostly due to malaria infestation and wound sepsis. The overall crude morbidity rate was $60.8 \%$ which was far higher than the one reported by Anzaku in Jos. ${ }^{10}$ Majority of these morbidities were minor complications necessitating no intervention. There was no case of mortality.

The average number of days spent on admission was 9.7 days. The numbers of days ranged between 5 and 21days. Majority of the patients stayed for 5 to 9 days. This was comparable with the study in Kano and Jos. ${ }^{7,10}$ The average hospital stay of 9.7 days was higher than the average reported in Gombe North East Nigeria and Portugal. ${ }^{9,21}$ Patients who spent 10 days or more on admission were those who had bowel preparation prior to surgery or had blood transfusion due to anaemia from menorrhagia prior to surgery. Only very few of them were as a result of post-operative complications. The above was further supported by the average of 4.8 days which patients stayed on admission post-operatively. Most of the patients $(71.26 \%)$ were discharged home by the fourth post-operative day. This was possible because most of our patients had skin closure with subcuticular absorbable suture which does not require removal. Those who spent seven days or more were those who had their skin repaired with non-absorbable sutures, operated on for malignancies or had post-operative complications 


\section{Conclusion}

Total abdominal hysterectomy is a common gynaecological procedure and uterine fibroid is the most common indication. It offers total cure for many benign gynaecological disorders like uterine fibroids, premalignant cervical lesions, endometrial hyperplasia among others. Total abdominal hysterectomy is a safe gynaecological procedure and anaemia which was the most common complication in this study was sequel to the premorbid state of most of the patients rather than intra-operative blood loss. It is therefore important to health educate our women on need to present in the early stage of their disease in order to prevent complications before seeking treatment, during and following treatment. Proper optimization of the patients prior to surgery is also mandatory.

\section{Acknowledgement: None.}

Financial Support: None

\section{Disclosure of Conflict of interest: None}

Ethical consideration: Ethical approval was sought and obtained from the Hospital Research and Ethical Committee.

\section{References}

1. Hammer A, Rositch AF, Kahlert J, Patti E. Gravitt PE, Blaakaer J, et al. Global epidemiology of hysterectomy: possible impact on gynecological cancer rates. AJOG, 2015: 213(1); 23-29.

2. Mukhopadhaya N, Manyonda IT. The hysterectomy story in the United Kingdom. J Midlife Health. 2013; 4(1): 40-41.

3. Keshavarz H, Hillis SD, Kieke BA, Marchbanks PA. Hysterectomy surveillance-United States, 1994-1999. MMWR CDC Surveill Summ. 2002;51:1-8

4. Stang A, Merrill RM, Kuss O. Hysterectomy in Germany: a DRG-based nationwide analysis, 2005-2006. Dtsch Arztebl Int. 2011;108(30):508-14.

5. Stankiewicz A; L. Pogany L; Popadiuk C. Prevalence of self-reported hysterectomy among Canadian women, 2000/2001-2008. Public health agency of Canada. 2014:34(1).

6. Arowojolu AO. Hysterectomy. In: Okonofua F, Odunsi K (ed.). Contemporary Obstetrics and Gynaecology for Developing Countries. Benin City. Women's Health and Action Research Centre. 2003: 227 - 242.

7. Rabiu A, Habib R. Elective abdominal hysterectomy: Appraisal of indications and complications at Aminu Kano Teaching Hospital - An 8-year review. Trop J Obstet Gynaecol. 2017;34:224-8.

8. Oseki C, Osaikhuwuomwan JA. A Review of indications and outcome of total abdominal hysterectomy at a tertiary public health facility in Southern Nigeria. N Niger J Clin Res 2018;7:21-4.

9. Bukar M, Audu BM, Yahaya UR, Hysterectomy for benign gynaecological conditions at Gombe, north eastern Nigeria. Niger Med J. 200;51:35-8.

10. Anzaku AS, Musa J. Total abdominal hysterectomy for benign gynaecological conditions at a University Teaching Hospital in Nigeria. Niger J Med. 2012; 326-330

11. Wright JD, Herzog TJ, Tsui J, Ananth CD, Lewin SN, Yu-Shiang Lu et al. Nationwide Trends in the Performance of Inpatient Hysterectomy in the United States. Obstet Gynecol. 2013;122(2 0 1):233-24.

12. Usman HA, Sanusi IM, Kullima AA, Kawuwa MB. Hysterectomy for Gynaecological Conditions AtNguru, North Eastern Nigeria: A Retrospective Study. J. Med SciCli Res. 2012: 5(1); 17131-17138

13. Koledade AK, Oguntayo AO, Zayyan MS, Avidime S. Samaila MO, Adesiyun AG. Hysterectomies pattern a a tertiary healthcare center, northern Nigeria. Trop J Obstet Gynaecol 2018;35:184-7.

14. Ikechebelu JI, Mbamara SU, Ezike HA. Laparoscopically assisted vaginal hysterectomy in southeast Nigeria-case report. Niger J Med. 2009;18:107-9. 
15. Olusegun O. Badejoko KO, Babawale OO and Adebanjo BA. Total laparoscopic hysterectomy: A case report from ILE-IFE, Nigeria. Niger Med J. 2012; 53(4): 254256.

16. Akintobi A, Bello O, Asaolu O. Ikena G, Adebayo A. Laparoscopic supracervical hysterectomy and uterine morcellation: A case report from Asokoro District Hospital, Abuja.

17. Gante I, Medeiros-Borges C, Águas F. Hysterectomies in Portugal (2000-2014): What has changed? Eur J Obstet Gynecol Reprod Biol. 2017;208:97-102.

18. Desai S, Shuka A, Nambiar D, Ved R. Patterns of hysterectomy in India: a national and state-level analysis of the Fourth National Family Health Survey (2015 2016). BJOG. 2019126(4): $72-8$.

19. Obilahi-Abhulimen, Ibrahim IA., Barry OO. Hysterectomy in the Niger Delta of Nigeria: A Clinical Study of Indications and Outcome. Greener J Med Sci. 2013: 3 (5); 160-165.

20. Abisowo, O. Y., Olusegun, F. A., Ireti, A. O., Adeniyi, O. I., \& Oyedokun, O. Y. Hysterectomy in a Southwestern Tertiary Unit in Nigeria: A 5-Year Review. J Gynecologic Surgery, 2016; 32(6), 335-338.

21. Rositch AF, Nowak RG, Gravitt PE. Increased age and race-specific incidence of cervical cancer after correction for hysterectomy prevalence in the United States from 2000 to 2009. Cancer 2014; 120:2032-8. 